\title{
A Case Report of an Inverted Papilloma of the Prostatic Urethra and a Synchronous Low-Grade Papillary Carcinoma of the Bladder
}

\author{
Han-Seung Yoon ${ }^{1,2}$, A. Dempster ${ }^{2}$ \\ ${ }^{1}$ Department of Pathology, Dunedin School of Medicine, Otago University, Dunedin, New Zealand; ${ }^{2}$ Southern Community Laborato- \\ ries, Dunedin, New Zealand. \\ Email: han-seung.yoon@otago.ac.nz
}

Received July $18^{\text {th }}, 2012$; revised August $17^{\text {th }}, 2012$; accepted August $29^{\text {th }}, 2012$

\begin{abstract}
Inverted urothelial papilloma is a rare benign tumour and represents one of the urothelial lesions with inverted morphology. Accurate diagnosis and differentiation from other inverted lesions is important because its proper clinical management and expected clinical outcomes are distinctly different. Here we describe a case of a large inverted urothelial papilloma of the prostatic urethra and a synchronous non-invasive low-grade papillary urothelial carcinoma of the bladder in a 60-year-old man. We focus on the differential diagnosis of inverted urothelial papilloma.
\end{abstract}

Keywords: Inverted Papilloma; Papillary Urothelial Carcinoma; Prostatic Urethra; Urinary Bladder

\section{Introduction}

A number of well-recognized urothelial lesions with inverted morphology occur in the urinary tract. Among them inverted papilloma is a rare tumor accounting for less than $1 \%$ of all urothelial neoplasms [1-4]. Its recognition is important because of similarities to inverted urothelial carcinoma, especially in small biopsy specimens. Here we report a case of a large inverted papilloma and a concomitant low-grade non-invasive papillary urothelial carcinoma of the urinary bladder in a 60 -yearold male.

\section{Case Report}

A 60-year-old male complained of intermittent hematuria including occasional episodes of gross hematuria over the previous 14 months. A urine flow test showed obstructive features. Digital rectal examination showed an approximately 30 -gram clinically benign prostate. The PSA level was within the normal range. Urine cytology was negative. Cystoscopy showed a tiny papillary lesion just at the level of the trigone between the two ureteric orifices. The lesion was biopsied. Its histology showed a low-grade non-invasive papillary urothelial carcinoma (Figure 1).

Furthermore there was prolapse of the middle lobe of the prostate. Prostate chips weighing 4.5 grams were examined. Histology showed multiple fragments of cellular tissue a few of which had a normal urothelial sur- face. The majority of tissue fragments contained numerous nests of basaloid epithelial cells with prominent peripheral palisading (Figures 2 and 3). Areas of nonkeratinizing squamous differentiation were present (Figure 4). There were also frequent glandular structures or cystic spaces of varying size lined by flattened urothelial cells and basaloid epithelial cells containing variable amounts of homogenous eosinophilic material within the central lumen (Figure 5). Neither intestinal metaplasia nor goblet cells were present. Although the tumor showed

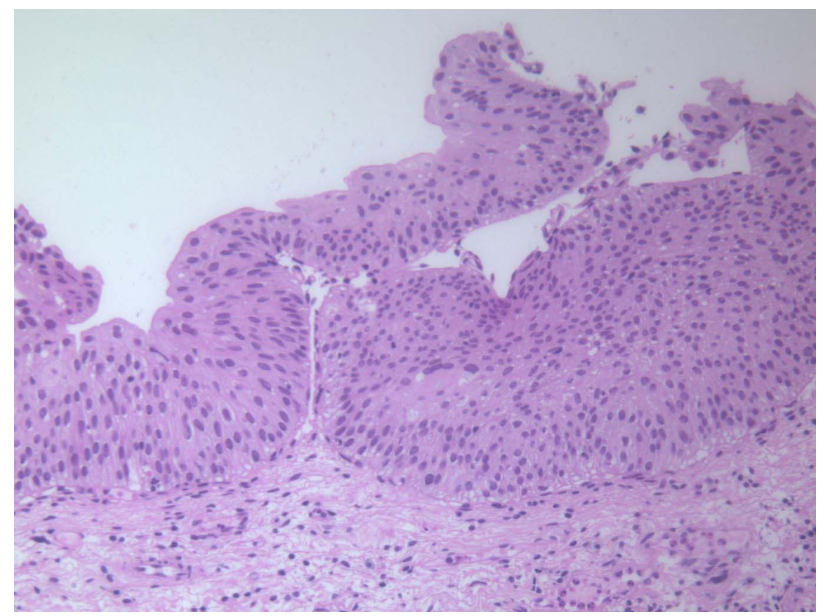

Figure 1. Low-grade non-invasive papillary urothelial carcinoma containing occasional thin fibrovascular stalks (H \& E 100×). 


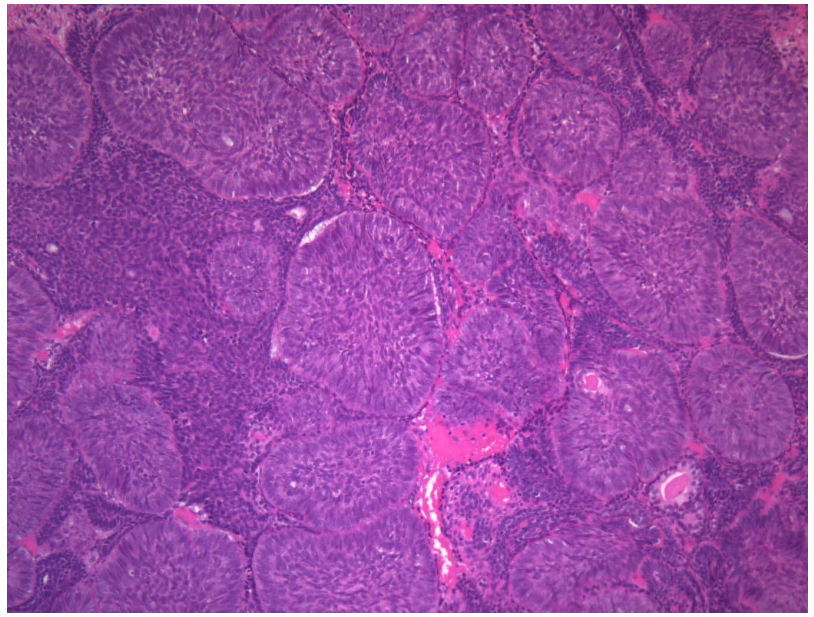

Figure 2. Numerous nests of basaloid epithelial cell (H \& E $100 \times)$.

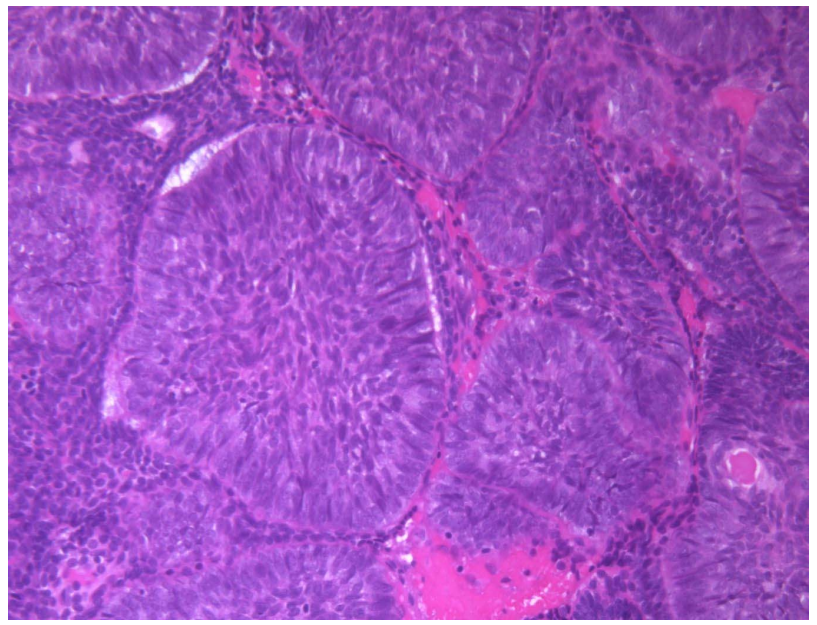

Figure 3. A higher magnified image of Figure 2 showing nests of basaloid cells with peripheral palisading (H \& E $200 \times)$.

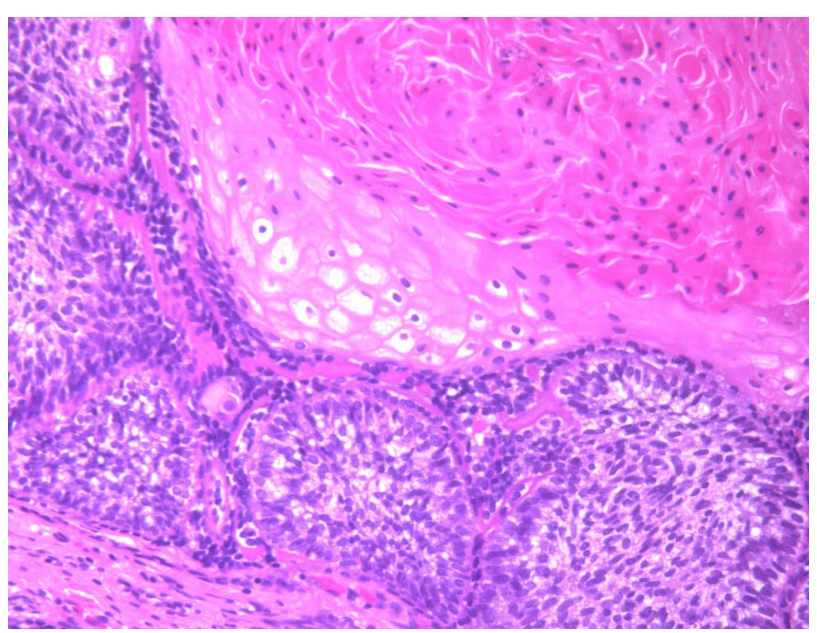

Figure 4. Some areas show prominent squamous differentiation (H \& E 200×). focal mild epithelial atypia and scattered mitotic figures, there was no evidence of invasive malignancy. The features were those of an inverted urothelial papilloma. None of the chips contained prostatic acinar glandular tissue.

Three weeks after the initial diagnosis, further prostate chips weighing 32.2 gram were transurethrally resected. Histological appearances of this material were identical to those of the first. In addition the 2nd specimen showed focal non-neoplastic areas of cystitis glandularis associated with a mild chronic inflammatory infiltrate (Figure 6). The tumor was diagnosed as an inverted urothelial papilloma, trabecular type associated with cystitis glandularis, originating from the prostatic urethra. No recurrence of vesical papillary urothelial carcinoma or prostatic urethral inverted papilloma has been recorded up to now.

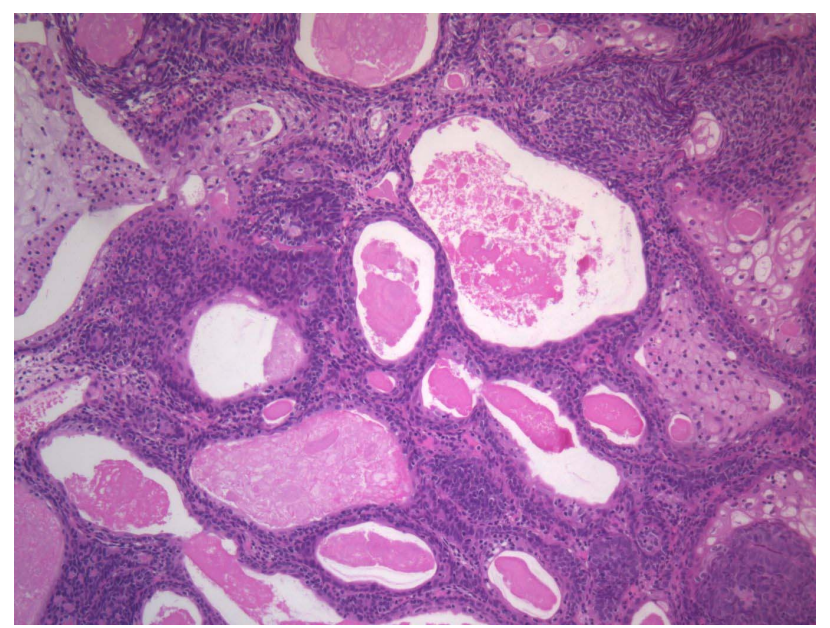

Figure 5. Frequent areas of glandular differentiation containing eosinophilic secretory materials (H \& E 100×).

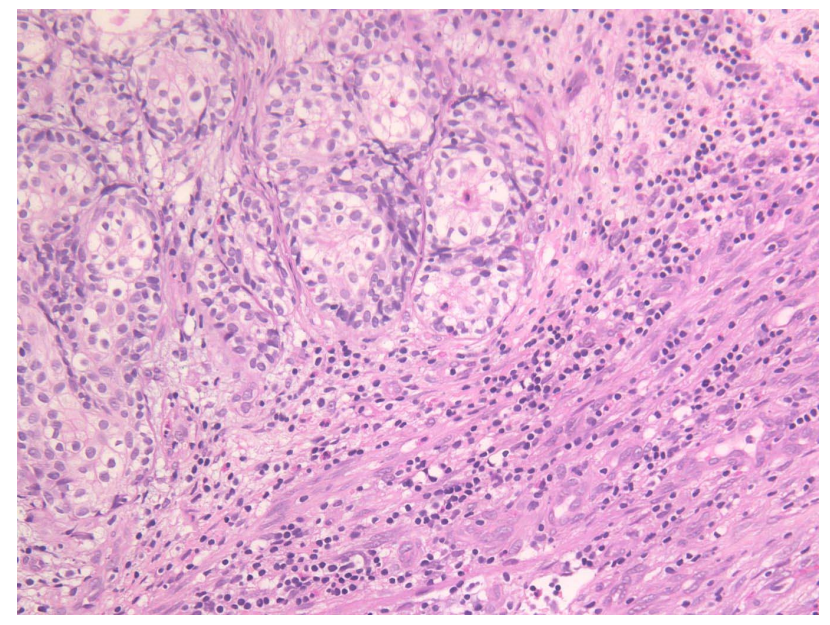

Figure 6. Focal non-neoplastic areas show features of cystitis glandularis in association with chronic inflammatory infiltrate (H \& E 200×). 


\section{Discussion}

Inverted papilloma of the urinary tract is a rare benign tumor most commonly diagnosed in older men presenting with hematuria or symptoms of lower urinary tract obstruction $[3,4]$. It is most frequently identified in the bladder neck or trigone as a polypoid growth with a smooth surface. These lesions are usually small $(<3 \mathrm{~cm})$ but can be large. Most are solitary although 1\% - 4\% may be multifocal.

Histologically there are two main subtypes of inverted papillomas; trabecular and glandular [1]. The former is characterized by widely branched, anastomosing cords of urothelial cells originating directly from the overlying transitional epithelium. The latter is characterized by multiple round to oval islands of proliferating urothelial cells together with pseudoglandular and true glandular structures, which are often connected with the surface urothelium.

Although inverted papilloma is generally regarded to be a benign neoplasm, sporadic cases of inverted papilloma with malignant features have been reported raising concern that inverted papilloma may be a precursor lesion of utorhelial malignancy [5-8]. However most of these patients had a history of previous or concurrent urothelial carcinoma. Inverted papilloma is associated with a low risk of recurrence (5\%), in marked contrast to the high recurrence rates of papillary urothelial carcinoma [3]. Sung et al. [2] reported only one recurrence among 75 patients with inverted papilloma (1.3\%) during a mean follow-up of 68 months after treatment. The authors recommend that complete transurethral resection appears to be adequate surgical therapy for inverted papilloma [2].

The present case showed an inverted papilloma of the prostatic urethra and a synchronous low-grade non-invasive papillary urothelial carcinoma of the bladder. Sporadic cases with inverted papilloma have been reported to show metachronous or synchronous urothelial carcinoma. Brown and Cohen in a series of 41 cases of inverted papilloma reported 2 patients (4.9\%) had a history of urothelial carcinoma and one of the 2 (2.4\%) was diagnosed with concomitant urothelial carcinoma [4]. The authors recommended postoperative surveillance because 2 patients developed urothelial carcinoma among 25 patients during a 9 - 25 months cystoscopic follow-up for non-recurrent inverted papilloma.

Differential diagnosis of inverted papilloma from other inverted urothelial lesions rests primarily on morphological criteria. Recognition of the possibility of inverted papilloma in the differential diagnosis remains the best safeguard against incorrect diagnosis [9]. The differential diagnosis includes non-neoplastic lesions such as von Brunn's nest, florid von Brunn's nest proliferation, cystitis cystica and cystitis glandularis as well as neoplastic lesions such as inverted urothelial carcinoma, nested variant of urothelial carcinoma and verrucous squamous cell carcinoma.

\section{REFERENCES}

[1] E. Kunze, A. Schauer and M. Schmitt, "Histology and Histogenesis of Two Different Types of Inverted Urothelial Papillomas," Cancer, Vol. 51, 1983, pp. 348-358. doi:10.1002/1097-0142(19830115)51:2<348::AID-CNCR 2820510231>3.0.CO;2-O

[2] M. T. Sung, G. T. MacLennan, A. Lopez-Beltran, R. Montironi and L. Cheng, "Natural History of Urothelial Inverted Papilloma,” Cancer, Vol. 107, No. 11, 2006, pp. 2622-2627. doi:10.1002/cncr.22311

[3] T. D. Jones, S. Zhang, A. Lopez-Beltran, J. N. Eble, M.-T., Sung, G. T. MacLennan, R. Montironi, P.-H. Tan, S. Zheng, L. A. Baldridge and L. Cheng, "Urothelial Carcinoma with an Invereted Growth Pattern Can Be Distinguished from Inverted Papilloma by Fluorescence in Situ Hybridization, Immunohistochemistry, and Morphologic Analysis,” American Journal of Surgical Pathology, Vol. 31, No. 12, 2007, pp. 1861-1867.

[4] K. B. Hodges, A. Lopez-Beltran, G. T. MacLennan, R. Montironi and L. Cheng, "Urothelial Lesions with Inverted Growth Patterns: Histogenesis, Molecular Genetic Findings, Differential Diagnosis and Clinical Management," BJU International, Vol. 107, No. 4, 2010, pp. 532-537. doi:10.1111/j.1464-410X.2010.09853.X

[5] K. Asano, J. Miki, S. Maeda, T. Naruoka, H. Takahasi and Y. Oishi, "Clinical Studies on Inverted Papilloma of the Urinary Tract: Report of 48 Cases and Review of the Literature,” Journal of Urology, Vol. 170, No. 4, 2003, pp. 1209-1212. doi:10.1097/01.ju.0000085342.15918.d7

[6] S. Picozzi, S. Casellato, G. Bozzini, D. Ratti, A. Macchi, B. Rubino, G. Pace and L. Carmignani, "Inverted Papilloma of the Bladder: A Review and an Analysis of the Recent Literature of 365 Patients," Urologic Oncology, 2012, in Press. doi:10.1016/j.urolonc.2012.03.009

[7] M. Eiber, J. M. van Oers, E. C. Zwarthoff, et al., "Low Frequency of Molecular Changes and Tumor Recurrence in Inverted Papillomas of the Urinary Tract,” American Journal of Surgical Pathology, Vol. 31, No. 6, 2007, pp. 938-946. doi:10.1097/01.pas.0000249448.13466.75

[8] L. F. Altaffer III, S. Y. Wilkerson, G. H. Jordan and D. F. Lynch, "Malignant Inverted Papilloma and Carcinoma in Situ of the Bladder," Journal of Urology, Vol. 128, No. 4, 1982, pp. 816-822.

[9] A. L. Brown and R. J. Cohen, "Inverted Papilloma of the Urinaru Bladder,” BJU International, Vol. 107, Suppl. 3, 2011, pp. 24-26. doi:10.1111/j.1464-410X.2011.10046.X 